\title{
PUBERTAD PRECOZ Y TUMORACIÓN TORÁCICA: PRESENTACIÓN DE UN CASO
}

\author{
María Nataly Laredo Reyna1,a, Juan Manuel Falen Bogio ${ }^{2, b}$, Roxana Lipa Chancolla, ,c, \\ Oswaldo Núñez Almache ${ }^{1, d}$, Paola Pinto1,a, Oscar Espinoza Robles, ${ }^{1, a}$, Eliana Chávez ${ }^{1, a}$, \\ María Isabel Rojas Gabulli1,2,b, Carlos Del Aguila Villar, ${ }^{1,2, a}$
}

\begin{abstract}
RESUMEN
Se reporta el caso de un paciente de 7 años de edad, que inicia su enfermedad con disnea progresiva, el desarrollo genital, de acuerdo con los criterios de Marshall y Tanner, muestra un estadio G2 VP3. En el tórax se halló una tumoración de bordes regulares y definidos, con presencia de calcificaciones y áreas quísticas de contenido heterogéneo. Las determinaciones basales de $\mathrm{FSH}$, LH y testosterona fueron de $<10 \mathrm{mUI} / \mathrm{mL}, 12,2 \mathrm{mUl} / \mathrm{mL}$ y $724 \mathrm{ng} / \mathrm{dL}$, respectivamente. La determinación de la $\alpha$-feto proteína fue de $145,1 \mathrm{ng} / \mathrm{mL}$. La exéresis del tumor mejoró el cuadro respiratorio, la remisión de los niveles hormonales y la detención del proceso de pubertad precoz. El estudio anatomopatológico de la tumoración mediastinal correspondió a un tumor de células germinales con componente predominante de teratoma maduro y coriocarcinoma. La pubertad precoz de etiología neoplásica es una causa rara, su diagnóstico es primordial para aplicar un tratamiento oportuno.
\end{abstract}

Palabras clave: Pubertad precoz; Disnea; Tórax; Teratoma (fuente DeCS BIREME).

\section{EARLY PUBERTY AND THORACIC MASS: PRESENTATION OF A CASE}

\begin{abstract}
A case is reported of a 7 year old patient with progressive dyspnea and genital development according to Marshall and Tanner criteria at the G2 VP3 stage. A mass of regular and well-defined borders was found in the chest, with calcifications and cystic areas of heterogeneous content. Basal measurements of $\mathrm{FSH}, \mathrm{LH}$ and testosterone were $<10 \mathrm{mlU} / \mathrm{mL}, 12.2$ $\mathrm{mIU} / \mathrm{mL}$ and $724 \mathrm{ng} / \mathrm{dL}$, respectively. a-fetoprotein was $145.1 \mathrm{ng} / \mathrm{mL}$. Excising the tumor improved respiratory symptoms, diminished hormone levels and stopped the process of precocious puberty. Pathology of the mediastinal tumor corresponded to a germ cell tumor with a predominant component of mature teratoma and choriocarcinoma. Neoplastic causes of precocious puberty are uncommon; its diagnosis is essential in order to provide timely treatment.
\end{abstract}

Key words: Puberty, precocious; Dyspnea; Thorax; Teratoma (source: MeSH, NLM).

\section{INTRODUCCIÓN}

La pubertad precoz es una de las condiciones más comunes encontradas en la práctica de la endocrinología pediátrica, afecta hasta 29 por cada 100000 niñas al año (1) y se define como el desarrollo de caracteres sexuales antes de los 8 años en las niñas y de los 9 años en los varones.
La pubertad precoz puede ser central o periférica, según sea dependiente o independiente de $\mathrm{GnRH}$ respectivamente. La pubertad precoz central (PPC) es más frecuente en las mujeres que en los varones, y mientras que es predominantemente idiopática en las niñas, en los varones es generalmente de causa orgánica o patológica. La PPC ocurre en 1 de 5000 a 10000 niños, y es 5 a 10 veces más común en mujeres

Instituto Nacional de Salud del Niño. Lima, Perú.

Facultad de Medicina, Universidad Nacional Federico Villareal. Lima, Perú.

Médico pediatra; ${ }^{\mathrm{b}}$ médico endocrinólogo; ${ }^{\mathrm{c}}$ médico patólogo clínico; ${ }^{\mathrm{d}}$ médico endocrinologo pediatra

Recibido: : 28-11-13 Aprobado: 09-07-14

Citar como: Laredo Reyna MN, Falen Bogio JM, Lipa Chancolla R, Núñez Almache O, Pinto P, Espinoza Robles O, et al. Pubertad precoz y tumoración torácica: presentación de un caso. Rev Peru Med Exp Salud Publica. 2014;31(3):588-94. 
que en varones ${ }^{(2)}$. El término pubertad precoz periférica (PPP) se utiliza para designar cuadros clínicos de pubertad precoz (aparición de caracteres sexuales junto a adelanto de la maduración ósea y aceleración del crecimiento) que no son mediados por el eje hipotálamohipófiso-gonadal; es decir, situaciones en las que no hay elevación de gonadotropinas.

La PPP es mucho más infrecuente que la PPC y puede ser de origen genético o adquirido. La PPP o independiente de $\mathrm{GnRH}$ obedece a diversas causas y puede ser isosexual y heterosexual, según que los caracteres sexuales sean concordantes con el mismo sexo genético o no. Esta última da lugar a pubertad precoz virilizante en la niña y feminizante en el niño. La PPP en las niñas puede deberse a tumores ováricos (de la granulosa, de la teca, teratomas, disgerminomas), quistes ováricos, hiperplasia suprarrenal congénita, tumores suprarrenales (isosexual o heterosexual), síndrome de McCune Albright, o administración de estrógenos. Mientras que en los varones la pubertad precoz periférica suele deberse a tumores testiculares, hiperplasia suprarrenal congénita, tumores suprarrenales, tumores productores de hCG, síndrome de McCune Albright, o testotoxicosis ${ }^{(3)}$.

En estudios de grandes series, la causa subyacente de pubertad precoz es usualmente benigna, sin evidencia de lesiones orgánicas. Sin embargo, puede ser causada por tumores malignos y se describe como un signo de presentación de cáncer infantil en solo un pequeño número de informes de casos ${ }^{(4)}$. Los tumores de células germinales (TCG) pediátricos son raros pues representan el 3 a $4 \%$ de los cánceres de la niñez. Surgen a partir de células madre pluripotenciales, se producen en las gónadas y en sitios extragonadales. Los pacientes con
TCG suelen tener una distribución por edades bimodal, con un pico antes de los tres años de edad y un segundo pico durante la adolescencia. El subtipo histológico más común en las series pediátricas es el tumor del seno endodérmico ${ }^{(5)}$. Entre las causas neoplásicas de pubertad precoz se describen los tumores de células germinales (TCG), que son un grupo de tumores que muestran variaciones en la presentación clínica, las características histopatológicas y biológicas. A pesar de las profundas diferencias entre las subentidades histológicas de TCG, la denominación común refleja la célula de origen común de estos tumores, la célula germinal primordial. Se reporta que $4 \%$ de los TCG se originan en el mediastino, la mayoría son benignos y representan 6 a $18 \%$ de los tumores mediastinales en la infancia. Los TCG mediastinales, que son malignos, se presentan más raramente siendo los tipos descritos el carcinoma embrionario, el teratocarcinoma y el coriocarcinoma ${ }^{(6)}$. El propósito del artículo es dar a conocer el caso de un paciente en edad prepuberal que desarrolló pubertad precoz debido a un tumor de células germinales mediastinal.

\section{REPORTE DEL CASO}

Paciente de 7 años 9 meses de edad, de sexo masculino, quien presenta disnea de curso progresivo de tres meses de evolución y dolor torácico un mes antes de su admisión hospitalaria, que se localiza a nivel de la zona precordial y se irradia hacia el hombro izquierdo, de moderada intensidad, se incrementa con la respiración profunda y con la posición de decúbito dorsal. Asociado a estos síntomas se nota el crecimiento del vello púbico, cambio en el tono de la voz e incremento de la talla con un tiempo de evolución de 1 año 9 meses.

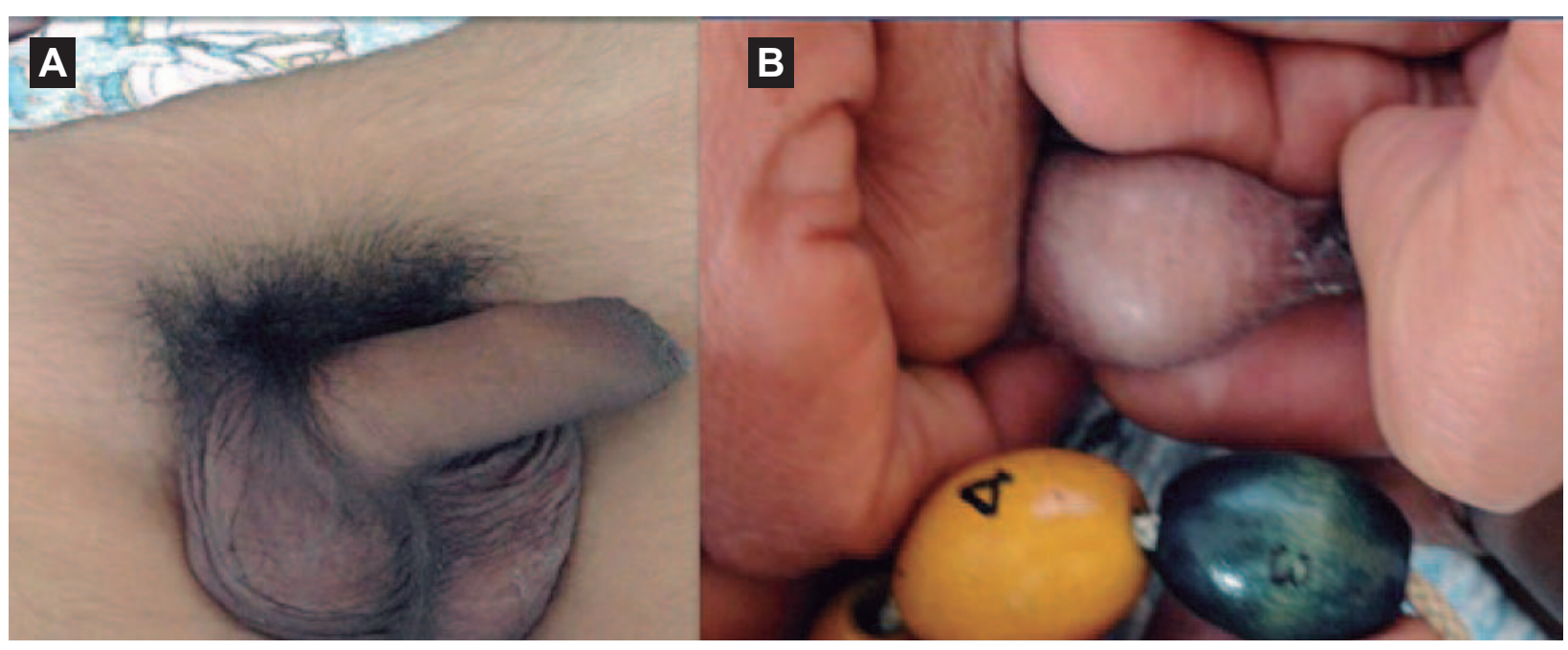

Figura 1. A. Desarrollo genital del paciente. B. Estadio Tanner G2 volumen testicular de $4 \mathrm{~mL}$ y vello púbico VP 3 


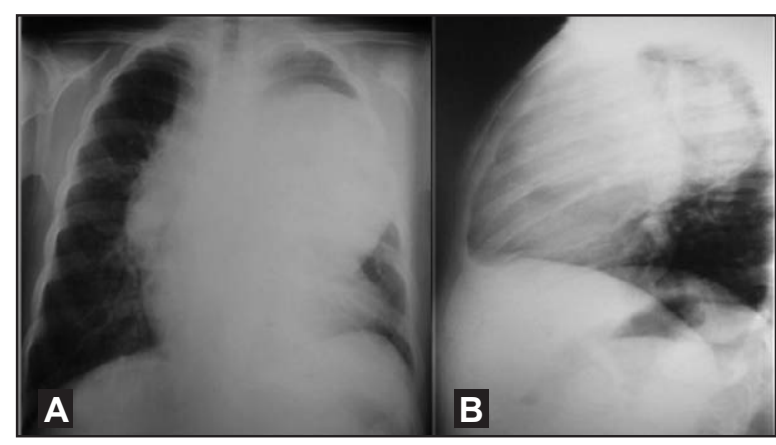

Figura 2. Radiografías frontal de tórax anteroposterior $(A)$ y lateral izquierda (B), que muestran tumoración que desplaza estructuras adyacentes al mediastino y atelectasia de los segmentos pulmonares II y VI izquierdos; retracción cardiaca y derrame pericárdico moderado

No se reportan antecedentes patológicos de importancia. Antecedentes familiares no contributorios. A la exploración física: paciente en decúbito dorsal activo, peso de $28,5 \mathrm{~kg}$ (95 percentil de las tablas del CDC para varones) y talla de $134 \mathrm{~cm}$ (>95 percentil de las tablas del CDC), el IMC fue de 16 (50 percentil de las tablas del $(D C)$. La frecuencia cardiaca era de 100 latidos por minuto y la respiratoria de 30 respiraciones por minuto, temperatura de $37^{\circ} \mathrm{C}$ y la presión arterial medida con mango adecuado para la edad fue de $90 / 60 \mathrm{mmHg}$. La voz era ronca, piel tibia, buen estado de hidratación, presencia de acné leve en la frente y presencia de bozo. La tiroides no era palpable.

Al examen del tórax se encontró matidez en los 2/3 superiores del hemitórax izquierdo y disminución del murmullo vesicular en la misma zona. Los ruidos cardiacos estaban disminuidos de intensidad. El abdomen era blando, depresible, presencia de ruidos hidroaereos. El hígado se palpaba a $2,5 \mathrm{~cm}$ por debajo del reborde costal derecho. La evaluación del desarrollo genital: G2, VP3, de acuerdo a los criterios de Marshall y Tanner (Figura 1). El examen neurológico fue de carácter normal.

La radiografía de tórax mostró imagen radioopaca en el mediastino anterior (Figura 2) y TEM de tórax que evidencia una tumoración de 172 × 91 × 113 $\mathrm{mm}$, de bordes regulares y definidos, con presencia de calcificaciones de regular tamaño y densidad, y áreas quísticas, correspondiente a tumoración de origen germinal con desplazamiento de estructuras adyacentes del mediastino; además, se encontró atelectasia adyacente a segmentos II y VI izquierdos, retracción cardiaca y derrame pericárdico moderado (Figura 3). Un primer estudio ecocardiográfico mostró derrame pericárdico anterior severo, con signos de pretaponamiento y presencia de tumor de gran tamaño que comprime el tronco de la arteria pulmonar; no se evidencia defectos cardiacos y la función de ventrículo izquierdo está conservada. Dos semanas después, la ecocardiografía de control mostró derrame pericárdico anterior de aproximadamente $150 \mathrm{~mL}$ de volumen, con signos de taponamiento y función ventricular izquierda conservada; el pericardio es normal, no se encuentran vegetaciones y la presión de la arteria pulmonar es normal. La edad ósea determinada por el método de Tanner-Whitehouse, versión 2, fue de 12 años.

Las determinaciones basales de $\mathrm{FSH}$, LH y testosterona fueron de $<10 \mathrm{mUl} / \mathrm{mL} ; 12,2 \mathrm{mUl} / \mathrm{mL}$ y $724 \mathrm{ng} / \mathrm{dL}$, respectivamente; mientras que la 17-hidroxiprogesterona fue de $1,52 \mathrm{ng} / \mathrm{mL}$. La determinación de marcadores tumorales arrojó los siguientes resultados: la a-feto proteína ( $\mathrm{\alpha FP}$ ) fue de $145,1 \mathrm{ng} / \mathrm{mL}$ (rango normalidad 0 - $10 \mathrm{ng} / \mathrm{mL}$ ) y el antígeno carcinoembrionario (ACE) de $4,43 \mathrm{ng} / \mathrm{mL}$ (rango de normalidad $0-5 \mathrm{ng} / \mathrm{mL}$ ). El estudio hematológico mostró 12740 leucocitos, hemoglobina $9,2 \mathrm{~g} / \mathrm{dL}$, velocidad de sedimentación de $60 \mathrm{~mm}$ a la hora y proteína $\mathrm{C}$ reactiva de $12,57 \mathrm{mg} / \mathrm{L}$. En los días

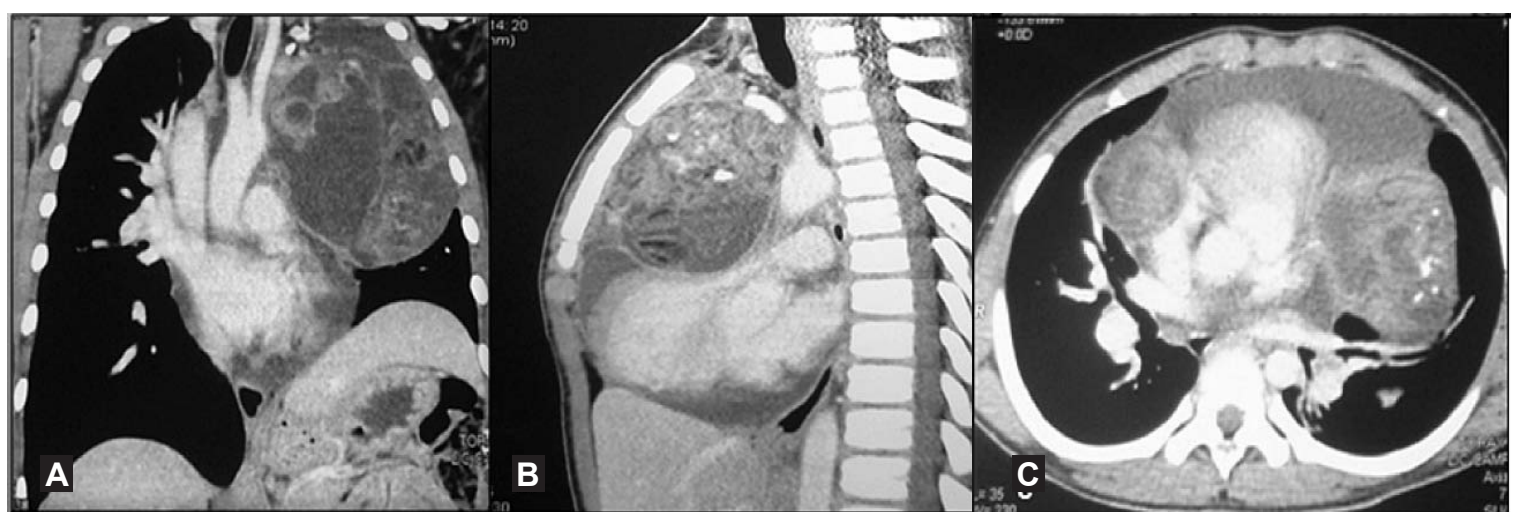

Figura 3. A TEM de tórax, donde se muestra una tumoración extensa en mediastino anterior de 172 mm x 91 x 113 mm, con bordes regulares definidos presentando calcificaciones gruesas y áreas de contenido quístico. B y $\mathrm{C}$ tumoración de origen germinal que desplaza y comprime las estructuras adyacentes del mediastino, y del ápice pulmonar izquierdo, produciendo retracción cardiaca, y derrame pericárdico moderado 


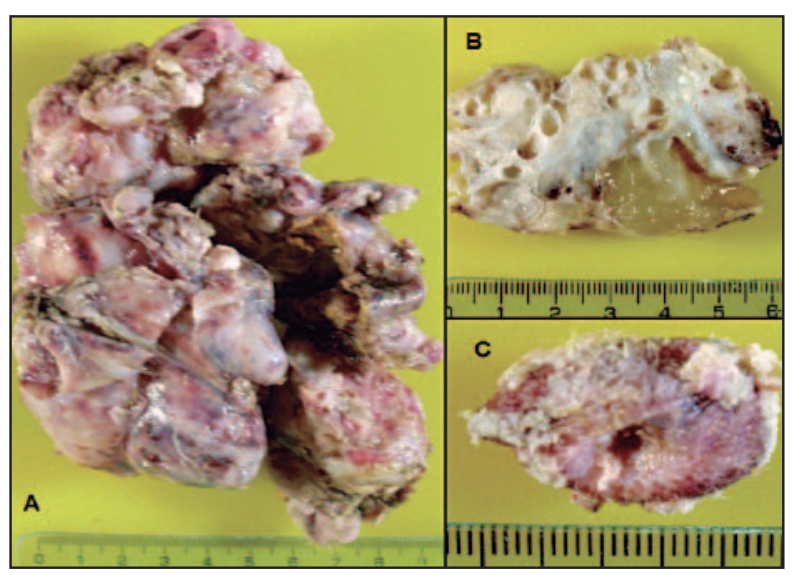

Figura 4. Tumor mediastinal: tumoración fragmentada de aspecto multilobular, superficie externa congestiva irregular. B.- Sección de tejido tumoral de aspecto multiquístico, cavidades con contenido seroso y mucoide, algunas tapizadas con material amarillento de aspecto sebáceo. Áreas sólidas heterogéneas de color pardo claro, aspecto fibroso y otra congestiva hemorrágica. C.- Nódulo de Rockitansky: nódulo de tejido de aspecto fibroso cubierto por material sebáceo y pelos

siguientes el paciente presentó incremento de la dificultad respiratoria y taquipnea, se le estabilizó para luego ser intervenido quirúrgicamente realizándose excéresis del tumor mediastinal en región anterior, el cual fue de naturaleza multiquística, con contenido mucoide y piloso, el diagnóstico postoperatorio inmediato fue de "teratoma", del cual se resecó el $80 \%$. La evolución fue favorable. Los exámenes hormonales posquirúrgicos mostraron LH 0,1 $\mathrm{mUI} / \mathrm{mL}$, FSH 0,1 mUl/mLy testosterona 2,61 ng/dL.

El estudio anatomopatológico reportó un tumor de $9,5 \times 8 \times 6 \mathrm{~cm}$, peso de $210 \mathrm{~g}$. Al corte, presenta múltiples quistes con contenido seroso y mucoide, áreas sólidas heterogéneas con contenido fibroso, otras de aspecto congestivo y hemorrágico; nódulos cubiertos con piel y anexos pilosos (Figura 4). El examen microscópico mostró componentes maduros y bien diferenciados de piel, anexos pilosebáceos, tejido graso, bronquial, intestinal, músculo y cartílago con extensas áreas de necrosis y hemorragia que corresponde a teratoma (Figura 5). En la Figura 6 se muestran células de sincitiotrofoblasto mezcladas con células del citotrofoblasto, que mostraron tinción inmunohistoquímica b-HCG positiva. Se concluye que la tumoración corresponde a tumor de células germinales con componente predominante de teratoma maduro y coriocarcinoma.

\section{DISCUSIÓN}

Las neoplasias son causas poco frecuentes pero importantes de pubertad precoz por lo que el reconocimiento temprano y el diagnóstico adecuado son cruciales. Los tumores, aunque infrecuentemente,

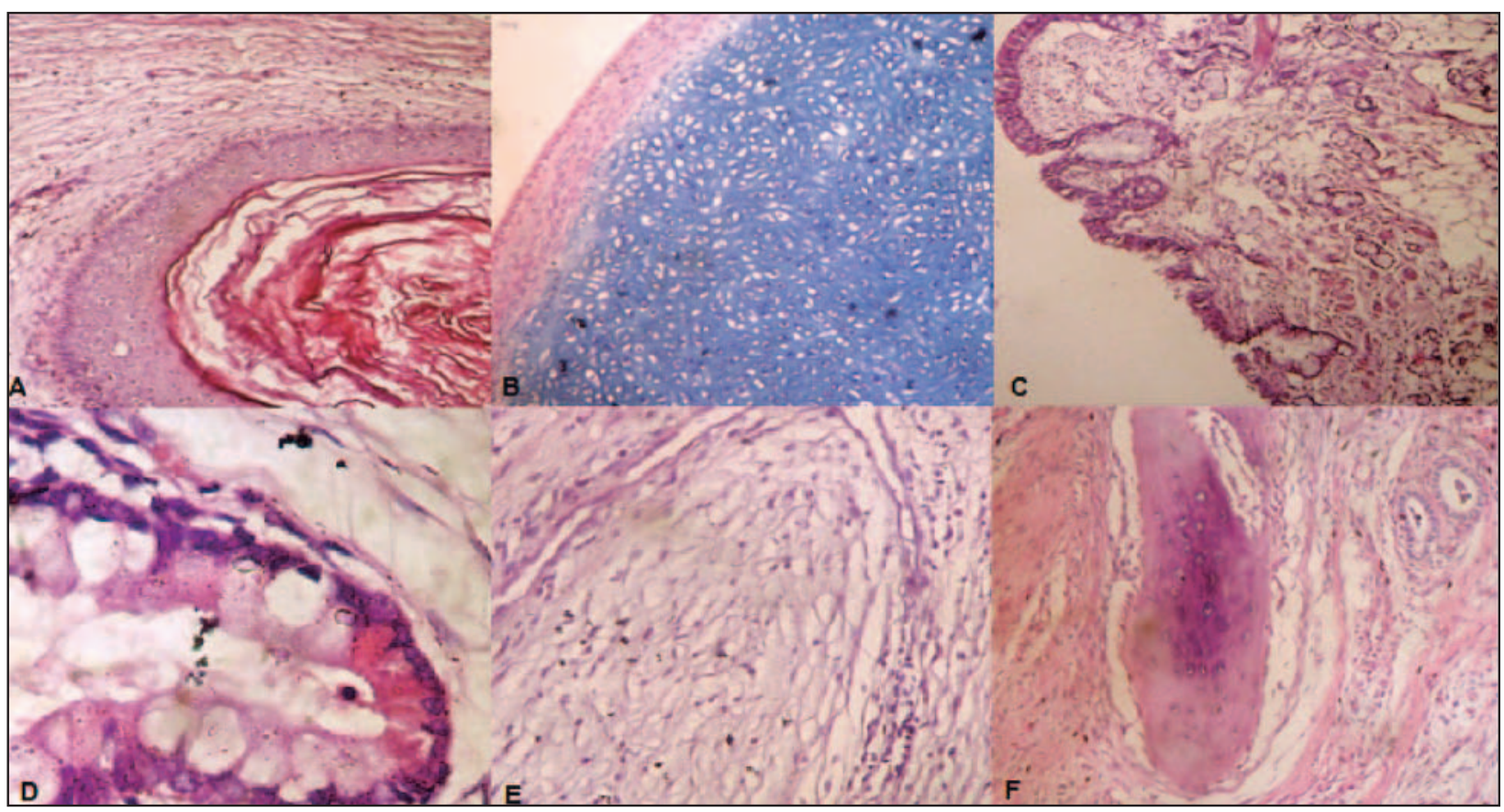

Figura 5. Tumor Mediastinal: A. Epitelio escamoso queratinizante (H \& E magnificación original x 200). B. Tejido cartilaginoso (H \& E magnificación original $x$ 100). C. Epitelio respiratorio (H \& E magnificación original $x$ 100). D. Epitelio intestinal (H \& E magnificación original x 1000). E. Tejido neural (H \& E magnificación original x 400). F. Tejido óseo (H \& E magnificación original x 200) 


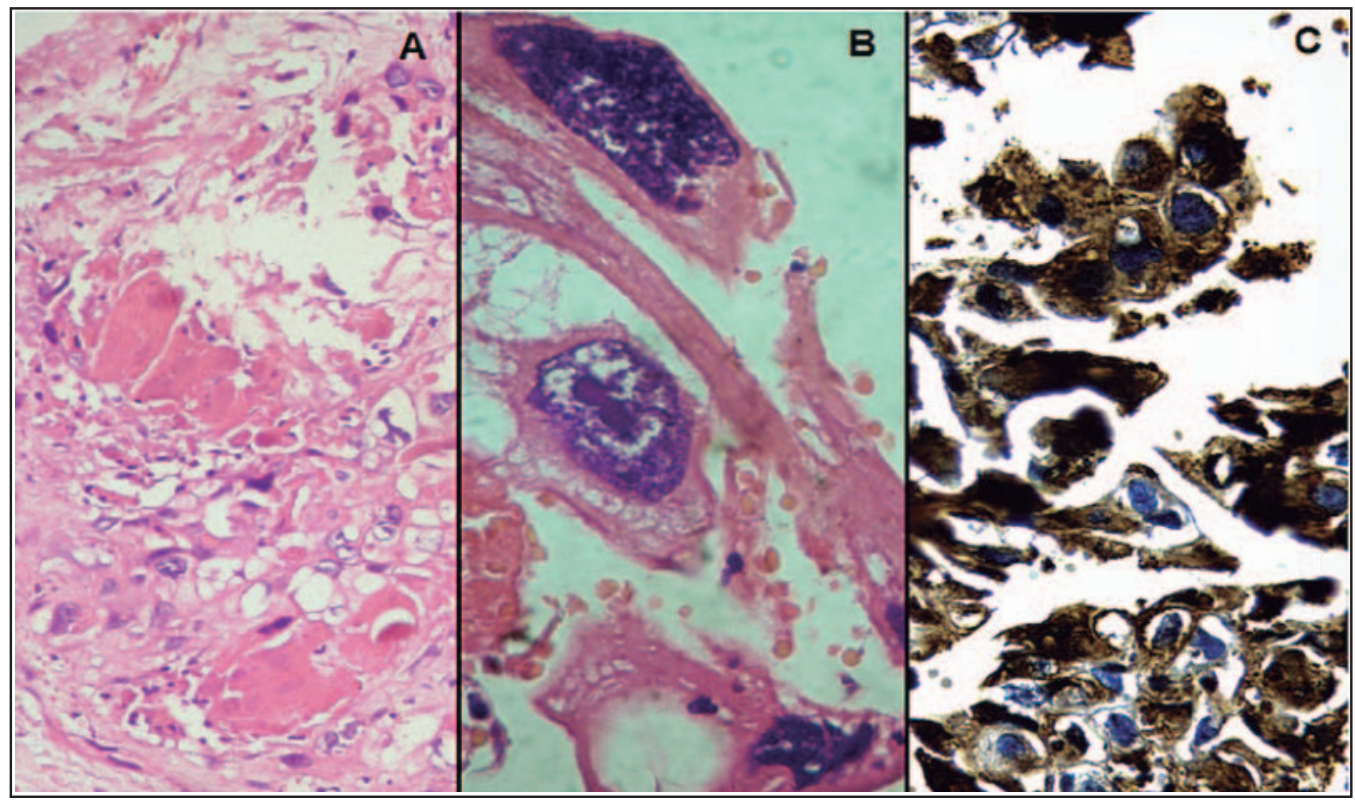

Figura 6. Tumor mediastinal: A. Nido de células del cito y sincitiotrofoblasto en un fondo hemorrágico $(H$ \& $E$ magnificación original $x$ 400). B. Células del Sincitiotrofoblasto, de gran tamaño, con pleomorfismo nuclear, nucléolo rojo prominente y citoplasma eosinófilo en un fondo hemorrágico (H \& E magnificación original x 1000). C. Tinción de Inmunohistoquímica positiva para HCG (Gonadotrofina Corionica Humana) en el citoplasma de las células del sincitiotrofoblasto . (IHQ Ac- HCG, magnificación original x1000)

pueden causar pubertad precoz central o periférica, y siempre deben considerarse en la evaluación inicial de esta patología. Así mismo, la pubertad precoz relacionada a neoplasias es una característica de presentación rara o poco frecuente de cáncer infantil. La evaluación de pubertad precoz en un niño es compleja $\mathrm{y}$, muchas veces, las neoplasias no son consideradas. Entre las causas neoplásicas de pubertad precoz, Wendt el al. (7) en un estudio realizado en el Saint Jude children's Hospital entre 1975 y 2011, reportan que de 13615 pacientes pediátricos con el diagnóstico de neoplasias, 24 niños $(0,2 \%)$ tuvieron pubertad precoz observada de 0 - 48 meses antes del diagnóstico de la neoplasia. Aunque es raro, las neoplasias pueden causar pubertad precoz y los signos de anormalidad puberal pueden ser malinterpretados o subestimados por un marcado retraso en la evaluación de pubertad precoz o falsamente diagnosticados de PPC idiopática. La evaluación básica de un niño con pubertad precoz debe incluir una historia médica completa, incluyendo la historia de la pubertad de los padres, la curva de la talla, y un examen físico completo centrado en el crecimiento, la escala de Tanner, la asimetría de los genitales y las gónadas, otros signos de pubertad (por ejemplo, cambios en la voz) evaluación de masa abdominal y de alteraciones neurológicas. Es de suma importancia la determinación de la edad ósea para completar una evaluación básica ${ }^{\left({ }^{8}\right)}$. Las características sexuales secundarias en pacientes prepúberes deben dar lugar a una evaluación para descartar una PP periférica incluyendo marcadores tumorales, hormonas sexuales, y las imágenes de gónadas, de glándula suprarrenal y de los posibles sitios de tumores productores de hCG.

Los tumores de células germinales del mediastino se encuentran raramente en la infancia; un número limitado de casos han sido reportados en los estudios, en comparación con las otras localizaciones anatómicas. Los TCG mediastínicos primarios representan el 6-24\% de todos los tumores del mediastino y el 3-4\% de todos los TCG. Se reporta que los TCG mediastínicos malignos se observan con relativa poca frecuencia y representan el $1-2 \%$ de todos los cánceres infantiles ${ }^{(9)}$. En relación a la fisiopatología los TCG pueden ocasionar pubertad precoz debido a la producción ectópica tumoral de la hormona hCG, una glicoproteína con una subunidad idéntica a la de la hormona luteinizante (LH). La hCG puede ser expresada por los TCG y debido a su similitud con LH, puede estimular la producción de testosterona por las células de leydig causando crecimiento peneano, crecimiento del vello púbico y axilar, y cambio en la voz en los varones. El tamaño testicular, frecuentemente, no se incrementa en ausencia de FSH. En mujeres, los folículos ováricos no se estimulan en ausencia de FSH, y la pubertad precoz inducida por hCG es menos común en tumores secretores de hCG por lo que la endocrinopatía paraneoplásica es más rara en niñas. 
Yalcin et al. ${ }^{(10)}$ reportaron entre 1973 y 2011, 24 casos de niños que fueron diagnosticados con TCG mediastinales, la edad media fue de 4,5 años, los síntomas iniciales fueron tos, anorexia, fatiga, fiebre y dolor torácico. La mayoría se localizaron en el mediastino anterior y el $54 \%$ fueron teratomas maduros, $16,7 \%$ fueron tumores del seno endodermal, $16,7 \%$ fueron teratomas inmaduros, $4,2 \%$ carcinoma embrionario, 4,2\% teratoma maligno, y $4,2 \%$ teratocarcinoma. Los pacientes con TCG mediastinales se presentan con síntomas respiratorios como tos y dificultad respiratoria. También pueden presentarse con dolor torácico y fiebre. En el presente caso, el paciente presentó como síntomas principales disnea progresiva, dolor torácico precordial y signos compresivos que suele presentar estos tumores a nivel mediastinal. Si bien los teratomas son benignos, suelen, algunas veces, tener carácter agresivo cuando se asocian a coriocarcinoma o carcinoma embrionario, siendo los marcadores tumorales de gran utilidad en el diagnóstico, como lo fue en este caso, que la a-fetoproteína estuvo elevada. Suelen ser más frecuentes en el sexo masculino y a mayor edad se incrementan los casos de malignidad.

El estudio de imágenes es muy importante, pues permite determinar la presencia de la masa tumoral y algunas de sus características, siendo la presencia de calcificaciones, como lo fue en este caso, un signo importante que contribuye al diagnóstico de teratoma. Tanto la tomografía computarizada, o bien la resonancia magnética nuclear, precisan mejor el diagnóstico por imágenes y hacen posible la diferenciación entre lesiones sólidas y quísticas (11). El tipo histopatológico del tumor hallado en el paciente fue el de tumor de células germinales mixto con componente a predominio de teratoma maduro y coriocarcinoma. Cabe destacar que $50 \%$ de los tumores de células germinales que se presentan en la población pediátrica son de naturaleza extragonadal y asientan con mayor frecuencia en la región sacrocoxigea y en el sistema nervioso central.

Los estudios inmunohistoquímicos realizados en el tumor extirpado al paciente mostraron la presencia de células del citotrofoblasto con presencia de b-HCG, lo que explica que este tipo de tumor pueda estimular las gónadas y desarrollar pubertad precoz que cesa cuando se extirpa el tumor. El coriocarcinoma mediastinal es una neoplasia que tiene su origen en la diferenciación extraembrionaria de células germinales malignas; raramente ocurre en forma pura, por lo general se produce a partir de tumores de células germinales mixto; histológicamente se caracterizan por una mezcla de citotrofoblasto, trofoblasto intermedio y sincitiotrofoblasto. En el caso que se presenta el tumor mediastinal resultó ser un TCG Mixto, 95\% teratoma y $5 \%$ coriocarcinoma, presentó células correspondientes a teratoma maduro y de coriocarcinoma, por lo que se considera un tumor de células germinales de histología mixta, que corresponde al $19 \%$ de los tumores de células germinales en pacientes en edad pediátrica.

El coriocarcinoma es una neoplasia altamente agresiva por su capacidad de invasión y diseminación. Los niveles séricos de marcadores tumorales (a-FP, ß-HCG y LDH) tienen valor pronóstico e implicaciones terapéuticas. Además, permiten monitorizar la respuesta al tratamiento, como sucedió en el caso del paciente de este caso. Marina et al reportan que el riesgo de mortalidad fue seis veces mayor en los pacientes $\geq 12$ años y con TCG malignos del tórax ${ }^{(12)}$. La quimioterapia ha mejorado la sobrevida en los pacientes pediátricos alcanzando niveles del $80 \%$.

Las neoplasias son causas poco frecuentes pero importantes de PP, y el reconocimiento precoz y el diagnóstico adecuado son cruciales. La PP puede ser malinterpretada como central idiopática $y$, en casos raros, la PPC puede ser inducida por PP periférica. Sin embargo, incluso cuando la LH y la FSH están elevadas, la testosterona o el estradiol están inapropiadamente altas o la respuesta es inadecuada a un régimen de supresión, se debe sospechar de un proceso patológico autónomo. En tales casos, el seguimiento estricto, los estudios de imágenes repetidos de sitios productores potenciales de hormonas pueden ser necesarios para la identificación de un tumor probable. La PP puede preceder el diagnóstico de malignidad por meses o años, y causas neoplásicas se deben considerar con anticipación para evitar un retraso en el diagnóstico del cáncer. El tratamiento de la neoplasia primaria resuelve la PP en los pacientes que sobreviven con un eje hipotálamo-hipófisis-gonadal intacto.

El estudio del paciente demostró la presencia de tumoración mediastinal responsable del cuadro clínico y los exámenes hormonales correspondían a activación de la actividad gonadal. Los estudios complementarios mostraron marcadores tumorales presentes. La excéresis del tumor mejoró el cuadro respiratorio y la remisión de los niveles hormonales y detención del avance del proceso de pubertad precoz. El estudio anatomopatológico de la tumoración demostró que se trataba de un teratoma de células germinales con componente predominante de teratoma maduro y coriocarcinoma, en el cual se demostró células de tipo sincitiotrofoblasto con reacción inmunohistoquímica de ß-HCG y probablemente de otras hormonas que producen estimulación de las células gonadotropas y células de Leydig, que una vez resecado el tumor hace que la LH, FSH y testosterona se normalicen. 
Se puede concluir que las causas neoplásicas de pubertad precoz son infrecuentes, sin embargo, son etiologías importantes de pubertad precoz por lo que el reconocimiento temprano y oportuno de estas presentaciones raras es primordial en el manejo de los pacientes. Así mismo, los TCG mediastinales en la infancia pueden inducir desarrollo puberal precoz que mejora con su resección. Los estudios de imágenes son básicos para el diagnóstico, el tratamiento es quirúrgico y el diagnóstico definitivo es anatomopatológico.

Contribuciones de autoría: $\mathrm{ML}, \mathrm{JF}, \mathrm{RL}$ y $\mathrm{ON}$ han participado en la concepción del artículo, la recolección de datos, su redacción y análisis e interpretación de la versión final. Además, CDA ha participado en el análisis e interpretación, la revisión crítica del artículo y aprobación de su versión final. EC, OE, PP y MR participaron en el análisis e interpretación del artículo y aporte de material de estudio

\section{REFERENCIAS BIBLIOGRÁFICAS}

1. Fuqua JS. Treatment and outcomes of precocious puberty: an update. J Clin Endocrinol Metab. 2013 Jun;98(6):2198-207. doi: 10.1210/ jc.2013-1024.

2. Carel JC, Leger G. Precocious Puberty. N Engl J Med 2008;358:2366-77.

3. Soriano Guillén L, Argente J. Pubertad precoz periférica: fundamentos clínicos y diagnóstico-terapéuticos. An Pediatr (Barc). 2012;76(4):229.e1-10.

4. Kaplowitz P. Clinical characteristics of 104 children referred for evaluation of precocious puberty. J Clin Endocrinol Metab. 2004 Aug;89(8):3644-50.

5. Castro-Feijóo L, Pombo M. Pubertad precoz. An Pediatr Contin. 2006;4(2):79-87.

6. Wendt $S$, Shelso J, Wright K, Furman W. Neoplastic causes of abnormal puberty. Pediatr Blood cancer. 2014 Apr;61(4):664-71. doi: 10.1002/ pbc. 24825 .

7. Mogensen SS, Aksglaede L, Mouritsen A, Sørensen K, Main KM, Gideon $\mathrm{P}$, et al. Diagnostic work-up of 449 consecutive girls who were referred to be evaluated for precocious puberty. J Clin Endocrinol Metab. 2011 May;96(5):1393-401. doi: 10.1210/ jc. 2010-2745.

8. Yalçın B, Demir HA, Tanyel FC, Akçören Z, Varan A, Akyüz C, et al. Mediastinal germ cell tumors in childhood. Pediatr Hematol Oncol. 2012 Oct;29(7):633-42.

9. Wu TT1, Wang HC, Chang YC, Lee YC, Chang YL, Yang PC. Mature mediastinal teratoma: sonographic imaging patterns and pathologic correlation. J Ultrasound Med. 2002 Jul;21(7):759-65.

10. Marina N, London WB, Frazier AL, Lauer S, Rescorla F, Cushing B, et al. Prognostic factors in children with extragonadal malignant germ cell tumors: a pediatric intergroup study. J Clin Oncol. 2006 Jun 1;24(16):2544-8.

11. Schneider DT, Calaminus G, Reinhard H, Gutjahr P, Kremens B, Harms D, et al. Primary mediastinal germ cell tumors in children and adolescents: results of the German cooperative protocols MAKEI 83/86, 89, and 96. J Clin Oncol. $2000 \mathrm{Feb}$;18(4):832-9.

12. Schneider DT, Calaminus G, Koch S, Teske C, Schmidt P, Haas RJ, et al. Epidemiologic analysis of 1,442 children and adolescents registered in the German germ cell tumor protocols. Pediatr Blood Cancer 2004 Feb;42(2):169-75.

13. Stephen MD,Zage PE, WaguespackSG. Gonadotropin-dependent precocious puberty: neoplastic causes and endocrine considerations. Int J Pediatr Endocrinol. 2011 Jan 27;2010(1):184502. doi: $10.1155 / 2010 / 184502$.

Correspondencia: Maria Laredo Reyna Dirección: Calle Ismael Frías 115- Dpto 301. San Borja. Lima, Perú

Teléfono: 996907710

Correo electrónico:laredomarita@yahoo.com

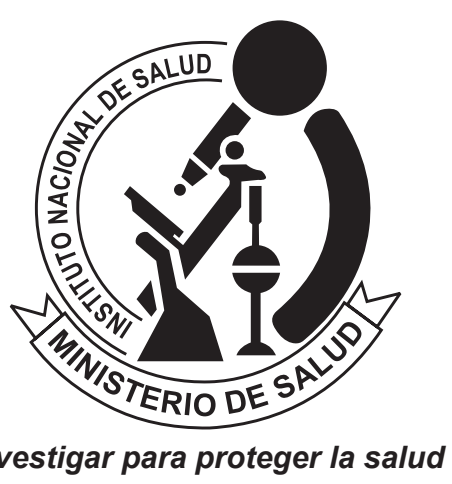

REVISTA PERUANA DE MEDICINA EXPERIMENTAL Y SALUD PÚBLICA CUMPLIENDO SUS METAS Y PROYECTÁNDOSE AL FUTURO 